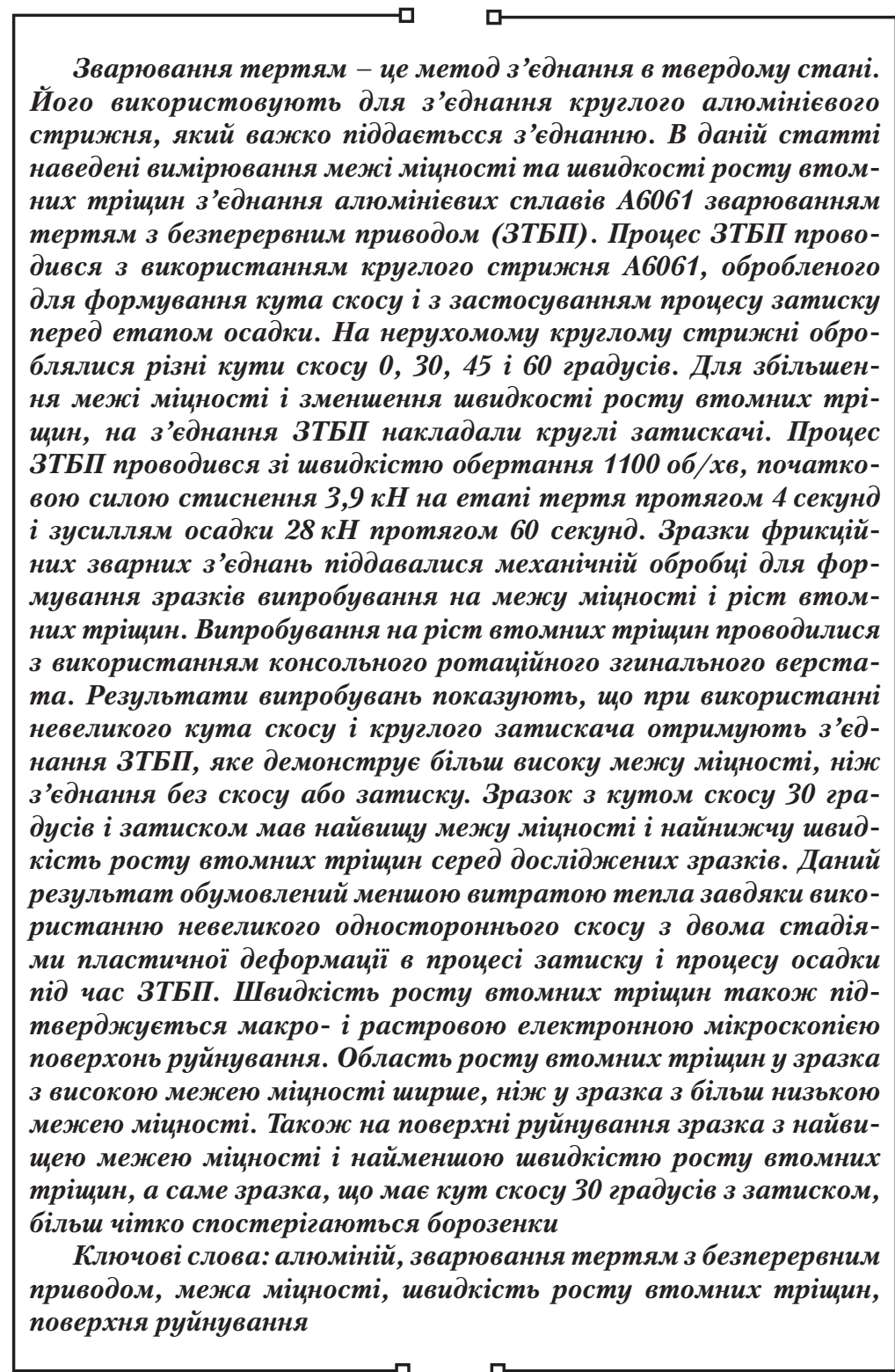

UDC 621.791

DOI: $10.15587 / 1729-4061.2019 .154384$

\section{TENSILE STRENGTH AND FATIGUE CRACK GROWTH RATE OF CHAMFERED AND CLAMPED A6061 FRICTION WELD JOINTS}

Yudy Surya Irawan Doctor of Engineering, Assistant Professor* E-mail: yudysir@ub.ac.id

Fakhri Razaq *

E-mail: fakhrirazaq1997@gmail.com Wahyono Suprapto Doctorate, Professor*

E-mail: wahyos@ub.ac.id

Bay S atria Wardana Master of Engineering,

Assistant Professor*

E-mail: wardhanabayu@ub.ac.id *Department of Mechanical Engineering

Brawijaya University Jalan. Mayjend Haryono, 167, Malang, Indonesia, 65145
Received date 27.11.2019

Accepted date 20.12.2019

Published date 26.12.2019
Copyright (c) 2019, Yudy Surya Irawan, Fakhri Razaq, Wahyono Suprapto, Bayu Satria Wardana This is an open access article under the CC BY license (http://creativecommons.org/licenses/by/4.0)

\section{Introduction}

Friction welding is one of solid-state joining methods. The friction welding method was first patented in the 1890s [1]. The method utilized an opportunity to generate heat using friction on both surfaces of metals and to make metallic joint [1]. The most common form of friction welding is rotary friction welding; others include linear friction welding, friction stir welding, and orbital friction welding. There are two kinds of rotary friction welding, which are known as continuous friction welding or continuous drive friction welding and inertia friction welding. In the continuous drive friction welding (CDFW) method, the energy to produce friction at the interface is continuously supplied by an electric motor with a constant rotational speed. In the case of the inertia welding method, the energy to produce friction is derived from a flywheel, which provides inertial energy storage, running at a predetermined initial speed. CDFW is a type of friction welding process for joining a round metal bar in the solid-state, which uses friction at the surface contact to generate heat and produce metallic joint. The CDFW technique uses one rotating part together with a stationary part that receives a compression force. When the compression force is applied to the stationary part, the coalescence of the rotating and the stationary parts yields friction and generates heat at the interface. The heat that occurs at the interface softens both parts and produces a flash that comes out from the interface, which can clean the interface. As the flash formed, the rotating part is stopped, and a higher final compressive force is applied to form a metallic joint at the interface of the specimens $[2,3]$.

The A6061 alloy is one of the aluminum alloys that contain magnesium and silicon. A6061 is usually available in the form of plates, round bars, and pipes. It is widely used to 
fabricate light structures, machine components, rail transportation components, and aircraft structures [4]. Joining round bars of aluminum alloys such us A6061 is difficult with the fusion welding method, due to the existence of brittle aluminum oxide together with the high thermal conductivity that prevents the heat at the interface from being sufficiently concentrated on melting the area to be joined [5]. A friction welding method such us CDFW is usually used in order to overcome the problems with joining aluminum. The process takes a short time and produces flash at the interface of the two specimens that have been joined [6]. Studying the friction welding of round metal bars is essential to produce stronger friction welding joints, especially for aluminum alloys such us A6061.

Therefore, the studies are devoted to improving the mechanical properties of friction weld joint of aluminum such as tensile strength and fatigue crack growth by modifying the process of friction welding or the specimen geometry. The expected result of the studies is the aluminum friction weld joint that has a higher tensile strength compared to the conventional method and slower fatigue crack growth rate so that it can be more resistant towards static and dynamic loadings.

\section{Literature review and problem statement}

In order to produce good quality of the CDFW joint, the essential parameters of the friction welding process are friction time, friction pressure, upset time, upset pressure, and rotation speed [7]. In the paper, it is found that certain friction times and friction pressures can yield maximum tensile strength of friction weld joint of AISI 1040 [7]. Meanwhile, the use of chamfer of the specimen as another parameter of the friction welding process to make friction welding joint between $\mathrm{Al}-\mathrm{Mg}-\mathrm{Si} / \mathrm{SiC}$ composite can increase the strength of the CDFW joint of the Al-Mg-Si/SiC composite [8]. Besides, the geometry of the specimen, such as a double chamfer [9] or one-sided chamfer [10], could also increase the tensile and torsion strength of CDFW joints of the aluminum A6061. A smaller chamfer angle could increase the strength of CDFW joint because the use of the chamfer angle can decrease the initial friction area and reduce the mechanical heat input at the interface of the CDFW joints. The use of one-sided chamfer on the specimen is preferable in terms of shorter preparation time [10].

As well as the static strength of the friction weld joint, such as tensile and torsion strength, it is essential to study the fatigue strength and fatigue crack growth rate of the friction welding joint. Fatigue is a failure that occurs due to a fluctuating load over long periods. Under this condition, the failure may occur even under stress that is below the yield strength of the materials [11]. Under fluctuating loading, which causes fluctuating stress on the defects present in materials, the defects act as stress concentrators. It can initiate a fatigue crack that may grow until it causes a final fracture. Therefore, research on the fatigue of friction weld joints is essential. The paper [12] reported the fatigue test using an Ono-type of rotary bending test and a cantilever rotary bending test with a notch on samples of friction weld A6061. It is found that the specimens fractured at the softened area or heat affected zone in the tensile strength and fatigue test. It appears that the structure at the weld interface influenced fatigue strength in the cantilever type test. A sound friction weld joint could be achieved if either the deformation heat input in the upset stage or the upset burn-off length exceeded a certain value [12]. The paper [13] reported the effect of friction welding on the fatigue properties of dissimilar friction weld joint of AISI 2205-AISI 1020. It was found that friction welding parameters, such as rotation speed, friction time, forging time, friction pressure, and forging pressure, affected the strength and fatigue properties of the joint. Selected parameters of the friction welding process can improve the fatigue properties of the friction weld joints of dissimilar steel [13]. In addition, the research was conducted on the very high cycle fatigue characteristic of the bulk amorphous alloy of $\mathrm{Zr}_{55} \mathrm{Al}_{10} \mathrm{Ni}_{5} \mathrm{Cu}_{30}$ (in at. \%) by performing fatigue testing using cantilever rotary bending test with a frequency of $52.5 \mathrm{~Hz}$ and stress ratio of -1 [14]. The crack initiated on the surface of the specimen and fatigue fractures could be clearly observed in the zone of stable fatigue crack growth. Stress intensity factors were also calculated during fatigue crack growth, and it was found that the fracture toughness of the bulk amorphous alloy was around 20-29 MPa.m ${ }^{1 / 2}$

As mentioned in previous research, the friction welding process is commonly conducted without a chamfer on the specimen and yields flash at the interface. The flash of the friction weld joint must be removed by a machining process that needs more time. It is the shortcoming of the conventional method of friction welding. Moreover, the use of no chamfer on the friction area will give high friction and resulting high heat input at the interface. To overcome these shortcomings, the friction welding process can be modified by using a one-side chamfer angle of the stationary specimen so that the initial friction area is less and can lower the initial heat input during friction welding. Besides, adding another process such as the clamping process at the interface can be able to reduce the flash. It is thought that a one-sided chamfer angle was applied to the stationary specimen. A double clamp driven by hydraulic power was used to press the flash at the interface after the friction stage, and then the upset pressure stage is applied along with the press of the clamp. Due to the double effect of plastic deformation on the interface from the clamping and the upset stage, it was expected that the tensile strength would increase and the fatigue crack growth rate would be slower with less flash at the interface of the friction weld joint. Most research is performed in no chamfer specimen and with the existence of the flash at the interface and there is no report about the effect of one-side chamfer angle and clamping stage on the tensile strength and fatigue crack growth rate. All this suggests that it is advisable to conduct a study on applying a one-sided chamfer angle on the stationary friction welding specimen and hydraulic double clamps at the interface to increase tensile strength and to reduce the flash of the weld joint. This paper reports the effects of a one-sided chamfer angle and a clamping process on the tensile strength and fatigue crack growth rate of friction weld joints of A6061, based on the tensile strength test, fatigue crack growth test, temperature measurement and fractography of the fracture surface of the specimens.

\section{The aim and objectives of the study}

The study aims to obtain higher tensile strength and lower fatigue crack growth rate of A6061 friction weld joint by using a one-sided chamfer angle on the stationary specimen and applying an hydraulic clamp to the weld joint. 
In order to achieve the aim, the following objectives were accomplished:

- to perform the tensile test of the specimen with clamping and no clamping during friction welding and to prove that the clamping method can increase the tensile strength of the weld joints and remove almost all of the flash;

- to conduct testing of fatigue crack growth rate using a cantilever rotary bending machine on the round bar of A6061 friction weld joint, both with clamping and no clamping;

- to make a correlation among the results of tensile strength test, fatigue crack growth rate testing, and fractography analysis of the surfaces of fractures caused by the cantilever rotary bending fatigue loading.

\section{Material and method of experiment}

The material used in this experiment was a commercial round bar of aluminum alloys A6061 with a tensile strength of $287 \mathrm{MPa}$. The chemical compositions of A6061 are shown in Table 1.

Table 1

The chemical compositions of aluminum alloys $\mathrm{A} 6061$

\begin{tabular}{|c|c|c|c|c|c|}
\hline $\begin{array}{c}\text { Compo- } \\
\text { nents }\end{array}$ & Weight \% & $\begin{array}{c}\text { Compo- } \\
\text { nents }\end{array}$ & Weight \% & $\begin{array}{c}\text { Compo- } \\
\text { nents }\end{array}$ & Weight \% \\
\hline $\mathrm{Al}$ & 97.95 & $\mathrm{Fe}$ & 0.272 & $\mathrm{Mn}$ & 0.020 \\
\hline $\mathrm{Mg}$ & 0.808 & $\mathrm{Cu}$ & 0.171 & $\mathrm{Cr}$ & 0.065 \\
\hline $\mathrm{Si}$ & 0.652 & $\mathrm{Zn}$ & 0.024 & Others & 0.038 \\
\hline
\end{tabular}

The bulk round bar of A6061 with a diameter of $22 \mathrm{~mm}$ was cut using a power hacksaw and coolant. First, CDFW specimens were prepared according to Fig. $1-4$ by machining with a CNC TU-2A machine. Fig. 1, $a, b$ show a rotating specimen with no chamfer and stationary specimen with no chamfer, respectively. Meanwhile, Fig. 2-4 show the rotating specimens with chamfer angles of 30, 45, and 60 degrees, respectively. The term «one-sided chamfer specimen» means that the stationary part has a chamfer while the rotating part has no chamfer.

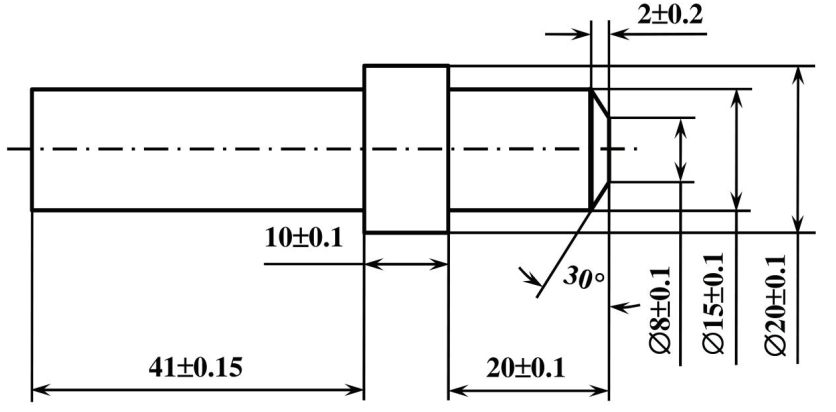

Fig. 2. Stationary friction-welding specimen with 30-degree of chamfer angle (unit: $\mathrm{mm}$ )

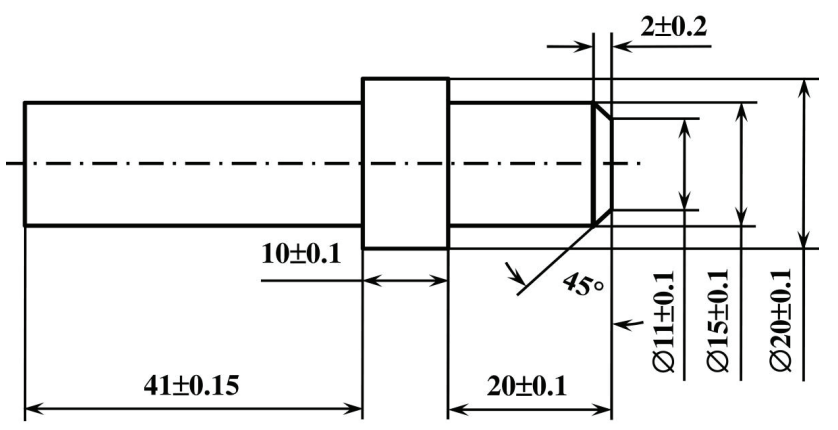

Fig. 3. Stationary friction-welding specimen with 45-degree of chamfer angle (unit: $\mathrm{mm}$ )

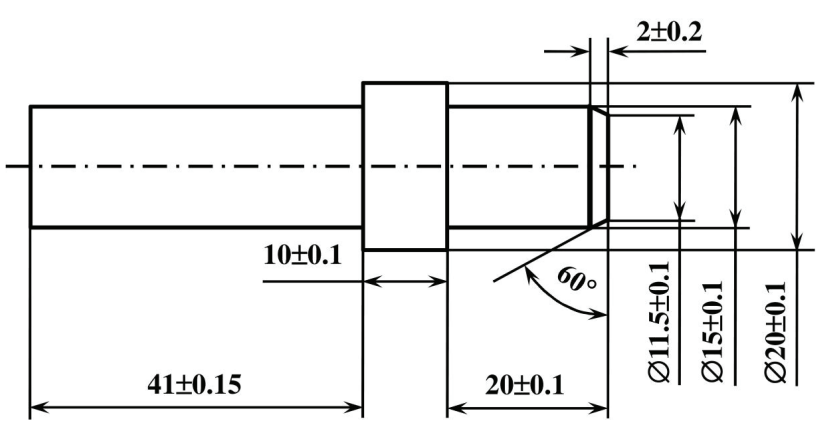

Fig. 4. Stationary friction-welding specimen with 60-degree of chamfer angle (unit: $\mathrm{mm}$ )

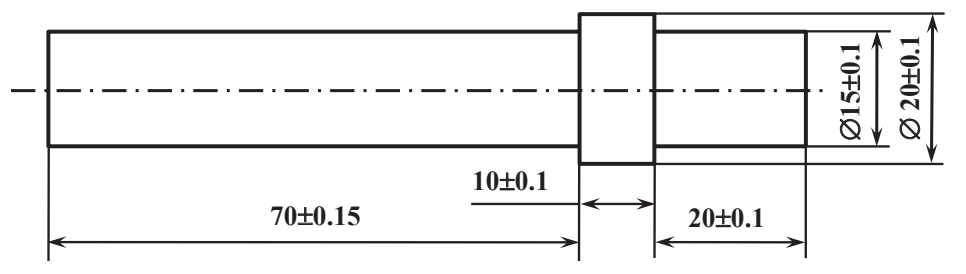

$a$

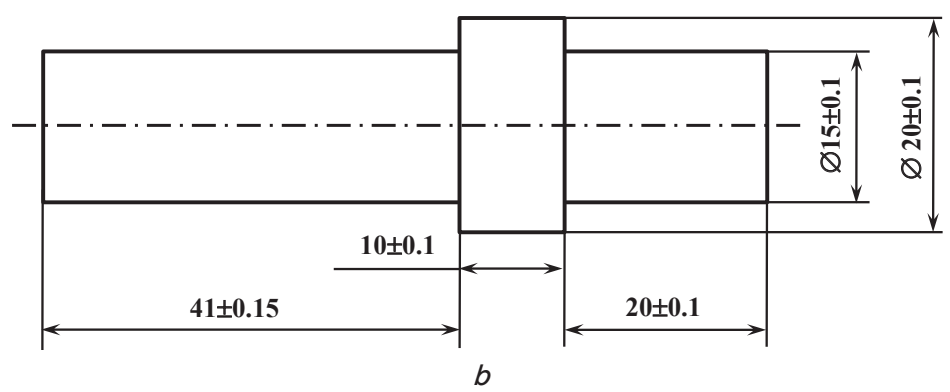

Fig. 1. The geometry of friction welding specimens: $a$ - rotating friction-welding specimen; $b$ - stationary friction-welding specimen with no chamfer, e. g., a chamfer angle of 0 degrees (unit: $\mathrm{mm}$ )
The CDFW process was performed using a lathe machine. The first step was to rotate the specimen at 1,100 rpm while applying a compression force of $3.9 \mathrm{kN}$ to the stationary specimen. After 4 seconds of friction time, the lathe machine was stopped, and the interface of the CDFW joint was clamped with a manual hydraulic pump for 10 seconds. Finally, a compressive force of $28 \mathrm{kN}$ was applied to the stationary specimen for 60 seconds. As the CDFW process ended, before the specimens were removed from the chucks, the specimens were allowed to cool in air. For comparison, the clamping process and no-clamping stage were applied only on the specimen without a chamfer angle (chamfer angle of 0 degrees). The specimen with no chamfer is commonly used and is better able to demonstrate whether a clamped or non-clamped specimen exhibits better tensile strength or other mechanical properties. During the CDFW process, a K-type thermocouple was attached to the stationary specimen at a distance of $20 \mathrm{~mm}$ from the CDFW joint to measure the maximum temperature of the specimen. 
After all the CDFW specimens were welded, the specimens were machined for tensile strength testing with the geometry shown in Fig. 5, based on the AWS standard [15]. Specimens for cantilever rotary bending fatigue testing were machined based on Fig. 6 [16].

Fig. 7 shows the schematic diagram of a cantilever rotary bending fatigue test machine, with the fatigue specimen attached to the chuck and a bending load applied to the opposite end. The electric motor has a revolution speed of $1,400 \mathrm{rpm}$ for fatigue testing.

A slit with a length of $2.5 \mathrm{~mm}$, a depth of $0.8 \mathrm{~mm}$, and a width of $0.2 \mathrm{~mm}$ was introduced in the weld joint of the fatigue specimen using an electrical discharge machine. All fatigue specimens were polished using emery papers with grades of $\# 800, \# 1,200$, and $\# 2,000$, subsequently. At the final stage of polishing, the center of the fatigue specimens was polished using autosol.

A fatigue loading of $26.4 \mathrm{MPa}$, equal to $12 \%$ of the highest tensile strength of the friction weld specimen, was used. A macro digital camera was used to capture the crack length at 1-minute intervals, and the number of cycles for each crack length was recorded. The crack depth was estimated from the fracture surface of the specimen. Fig. 8 illustrates a fatigue crack growth specimen with a side crack that has a length of $2 a$ and crack depth of $b$.

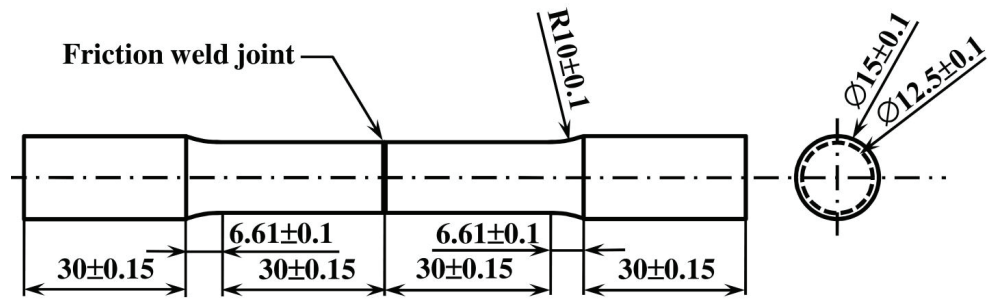

Fig. 5. Specimen for the tensile strength testing of the friction weld joint [15]

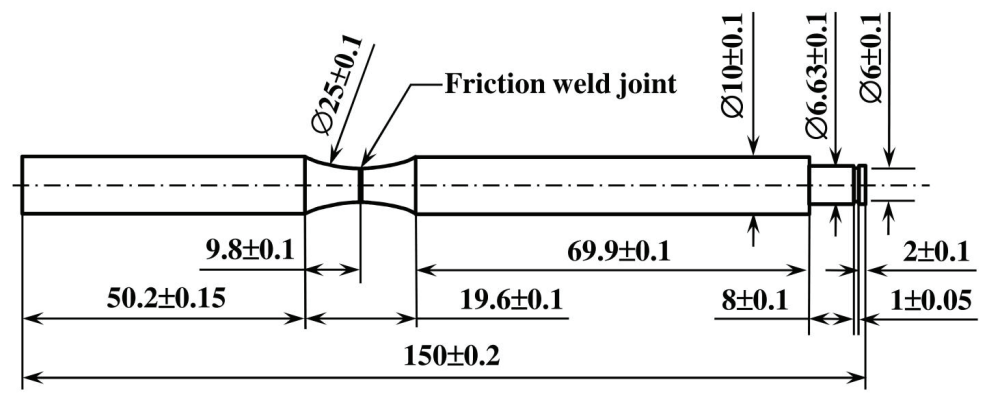

Fig. 6. Cantilever rotary bending fatigue testing specimen [16]

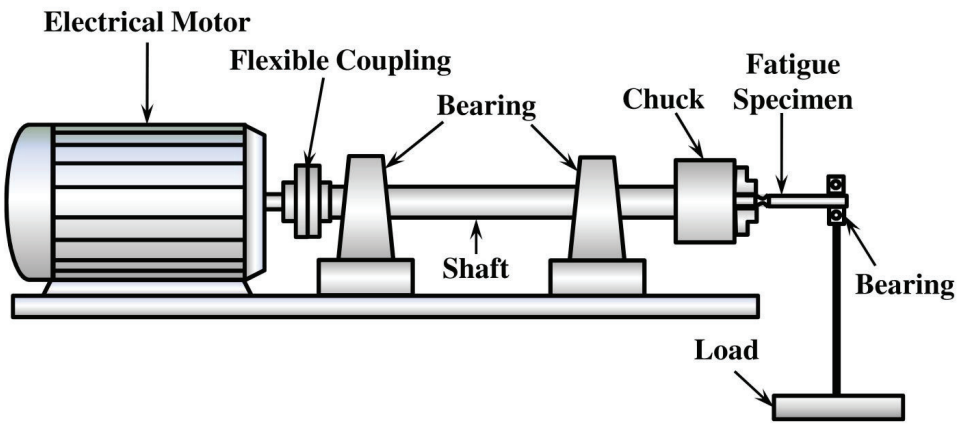

Fig. 7. Schematic diagram of the cantilever rotary bending test machine
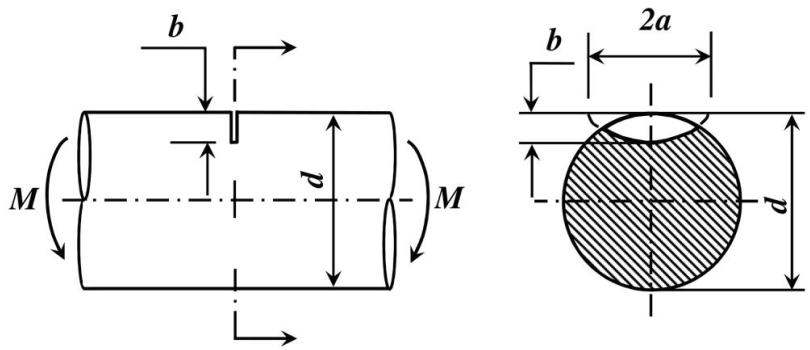

Fig. 8. Schematic diagram of the fatigue crack growth specimen with a surface crack; $M$ : bending moment, $b$ : crack depth, $2 a$ : crack length, $d$ : shaft diameter [14]

The stress intensity factor range (SIFR) of the crack, $\Delta K$, may be evaluated using Equation (1) when the stress ratio, $R=-1$, as occurs in the cantilever rotary bending fatigue testing machine [14].

$$
\Delta K=F_{I} \cdot \sigma_{a} \sqrt{\pi \cdot b},
$$

where $\sigma_{a}$ is the stress amplitude $\left(\sigma_{\text {maximum }}-\sigma_{\text {minimum }}\right), b$ is the crack depth, and the modification factor, $F_{I}$ is 0.66 . After calculating the SIFR, the ratio $d a / d N$ between the crack propagation $(d a)$ and the number of cycles $(d N)$ was calculated. The relationship between $d a / d N$ and $\Delta K$ was plotted in order to evaluate the fatigue crack growth rate.

Images of the fracture surface of the fatigue specimens were captured using a digital camera. For more in-depth analysis, a scanning electron microscope was used to observe the fracture surfaces of the fatigue crack growth specimens.

\section{Results of the experiment}

Fig. 9 shows friction weld joints obtained for various experimental conditions. The black line near the interface was drawn with a black marker for the positioning of the hydraulic clamp. The specimen with no chamfer and no clamping had flash surrounding the interface (Fig. 9, $a$ ); however, in the specimen with no chamfer, the clamp pushed nearly all of the flash to both sides of the specimens (Fig. 9, $b$ ). For the specimens with clamping, nearly all of the flash was removed to the sides of the specimen. For example, the specimen with a chamfer angle of 30 degrees was almost clean of flash (Fig. 9,c). The flash size of the specimens increased as the chamfer angle was increased. However, the flash did not surround the weld joint but instead was moved to the two sides of the weld joint, making easier to remove compared to the specimen without clamping.

The tensile strength test demonstrated that the specimen with no chamfer and no clamping had lower tensile strength than the one with no chamfer that was clamped, as shown in Fig. 10. The maximum tensile strength among the CDFW specimens occurred in the specimen with a chamfer angle of 30 degrees. It can be seen that the larger the chamfer angle, the lower the tensile strength of the CDFW specimen (Fig. 10). The 
lowest tensile strength occurred in the specimen with no chamfer (chamfer angle of 0 degrees). Notably, the CDFW joints specimens that underwent hydraulic clamping had higher tensile strength than the specimen with no chamfer and no clamping.
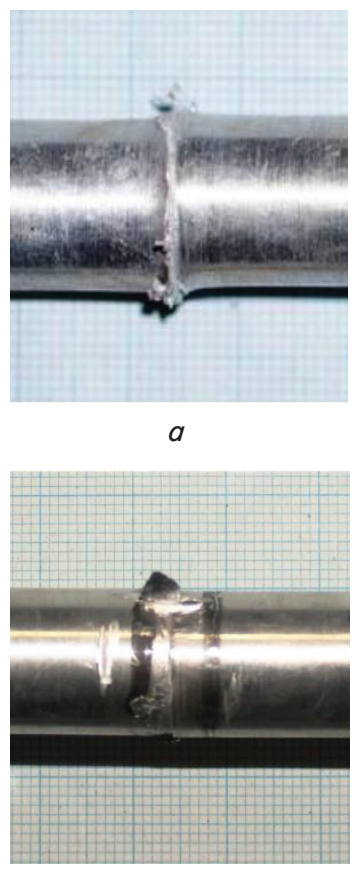

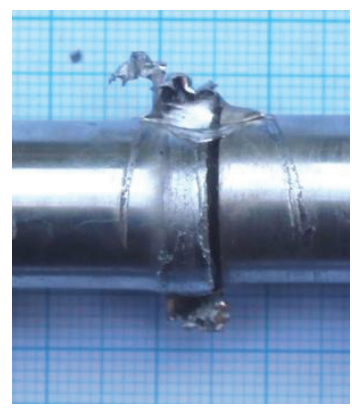

$b$

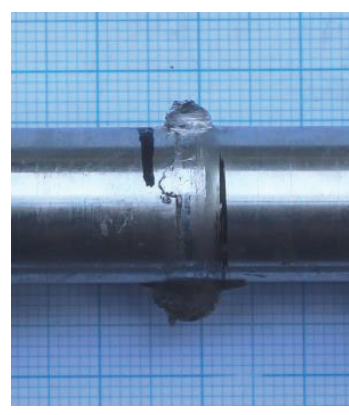

Fig. 9. Friction weld joint of A6061:

$a$ - no chamfer, without a clamp; $b$ - no chamfer, using a clamp; $c-30$-degree chamfer, using a clamp; $d-45$-degree chamfer, using a clamp

The results of the temperature measurement near the weld joints are shown in Fig. 11. The temperatures of the CDFW joint were all approximately $200^{\circ} \mathrm{C}$, which is slightly higher than the recrystallization temperature of aluminum A6061. For the specimens without a chamfer, the temperature of the clamped specimen was higher than that of the specimen without clamping. The maximum temperature near the weld joint for the chamfered specimens was lower than that of the specimen without a chamfer. The specimen with a chamfer angle of 30 degrees was found to have the lowest temperature.

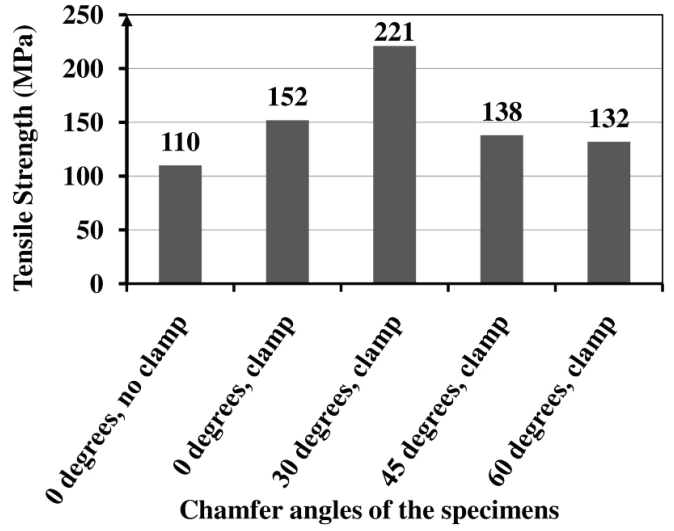

Fig. 10. Tensile strength of CDFW specimens with various chamfer angles

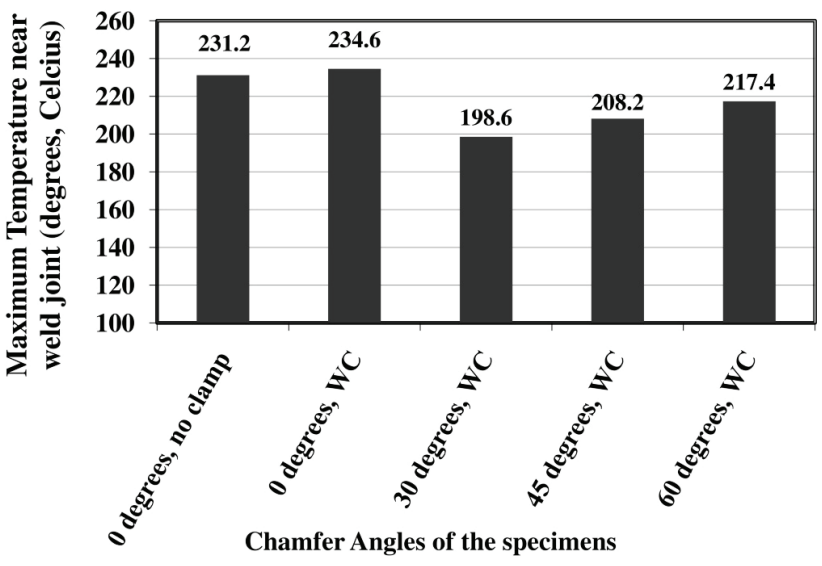

Fig. 11. Maximum temperature near friction weld joint (WC: with Clamping)

Fig. 12 shows the relationship between the crack length and the number of cycles obtained from fatigue crack growth testing using a cantilever rotary bending fatigue machine. The graph shows that the clamped specimen with a chamfer angle of 30 degrees took the largest number of cycles for the crack to grow, followed by the specimen with a chamfer angle of 0 degrees, 45 degrees, 60 degrees, and 0 degrees without clamping. Fig. 13 shows the relationship between the calculated values of $d a / d N$ and $\Delta K$ of the CDFW specimens. Based on equation (1), the same bending stress, the same crack length, and depth will give the same stress intensity factor range, $\Delta K$.

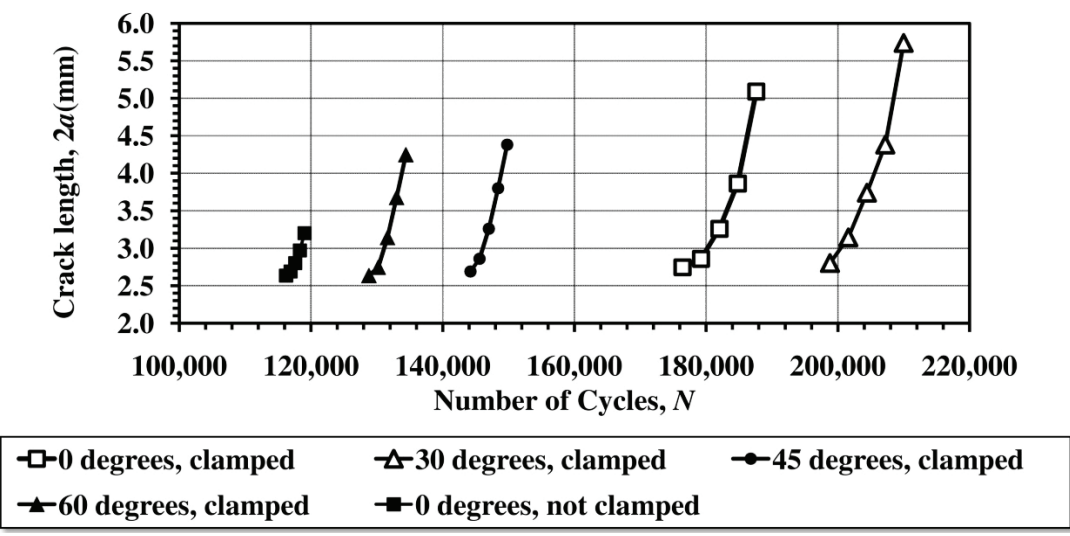

Fig. 12. Relationship between crack length, $2 a$ and the cycles of the fatigue crack, $N$ 


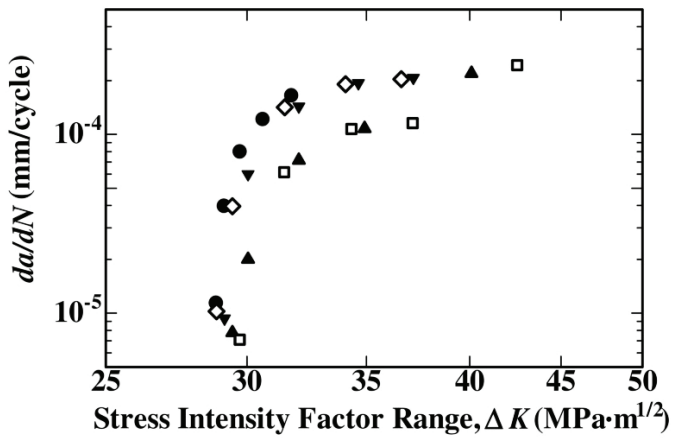

- O degrees no clamping $>45$ degrees with clamping

$\Delta \quad 0$ degrees with clamping $\diamond 60$ degrees with clamping

c 30 degrees with clamping

Fig. 13. Relationship between fatigue crack growth rate, $d a / d N$ and stress intensity factor range $\Delta K$ fer angle is $4.154 \mathrm{~mm}^{2}, 3.55 \mathrm{~mm}^{2}, 7.45 \mathrm{~mm}^{2}, 4.007 \mathrm{~mm}^{2}$, $3.68 \mathrm{~mm}^{2}$, respectively. It is found that the specimen without a chamfer, the area of the fatigue fracture region for the specimen without clamping, is smaller than that of the specimen with clamping. For the chamfered specimens, the widest fatigue fracture area is found on the CDFW specimen with a chamfer angle of 30 degrees. This implies that the fatigue crack propagated for a more extended time before the final static fracture occurred.

Fig. 15-17 show the scanning electron microscope (SEM) images of the fracture surfaces of the specimens with no chamfer, both without and with clamping, and the specimen with a chamfer angle of 30 degrees. Each figure shows a low-magnification image of the fracture surface and 1000x magnification images for three locations: near the initial slit, in the middle, and near the end of the fatigue fracture surface. The black arrow shows the direction of fatigue crack growth.
Fig. 13 shows that, for the same magnitude of SIFR, the crack growth rate $(d a / d N)$ was the slowest for the specimen with an angle of 30 degrees, followed by 0 degrees with clamping, 45 degrees, 60 degrees, and 0 degrees without clamping.

Fig. 14 shows the fracture surfaces of the various specimens. Two regions are visible: the fatigue fracture region and the static fracture region. The fatigue fracture region has a smooth and flat appearance arising from the initial slit. The static fracture region occurs when the specimen can no longer withstand the rotary bending fatigue loading and suffers a final fracture caused by the maximum bending stress. The fatigue fracture areas were measured using Image J software. The fatigue fracture area of the specimen with no chamfer with clamping and no clamping, 30 degrees chamfer angle, 45 degrees chamfer angle, 60 degrees cham-

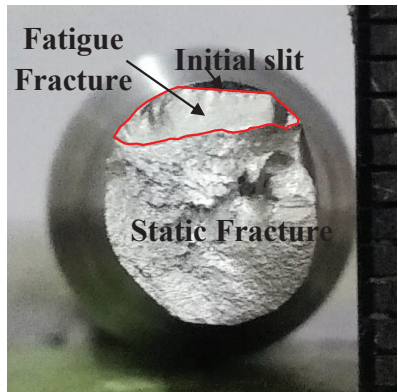

$a$

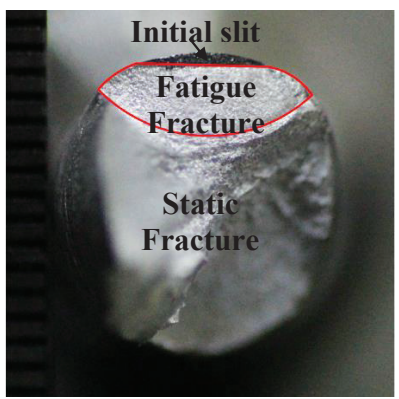

$d$

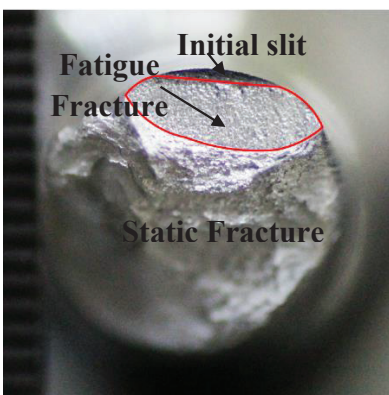

$b$

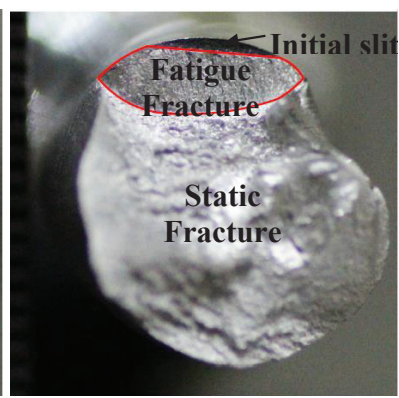

Fig. 14. Photos of the macro fracture surface of the specimens:

$a-$ Fracture surface of 0 degrees chamfer specimen without clamping; $b$ - Fracture surface of 0 -degree chamfer specimen with clamping (WC); $c-30$ degrees WC; $d-45$ degrees WC; $e-60$ degrees WC

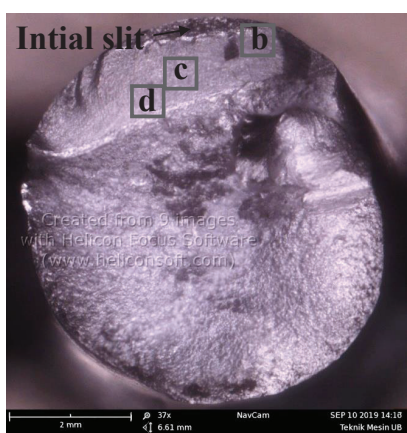

$a$

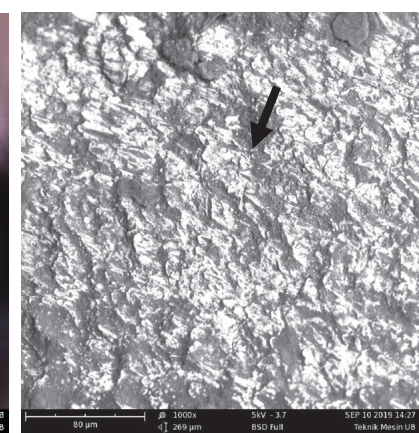

$b$

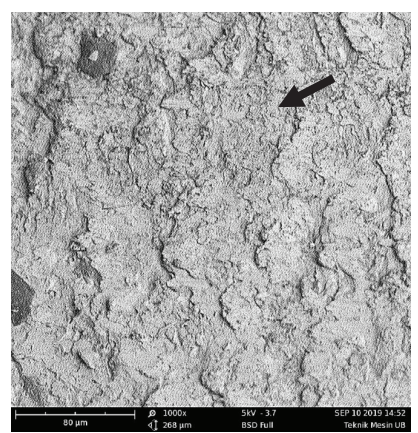

$c$

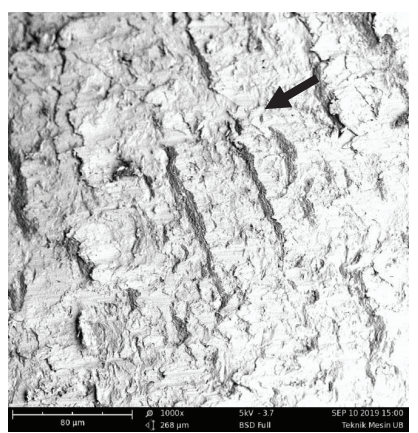

d

Fig. 15. SEM images of the fracture surface of the specimen with chamfer angle of 0 degrees without clamping:

$a$ - Overall SEM fracture surface; $b$ - Fatigue fracture surface near slit; $c$ - Fatigue fracture surface in the middle fracture surface; $d-$ Fatigue fracture surface near static/final fracture. (Black arrow is fatigue crack growth direction) 


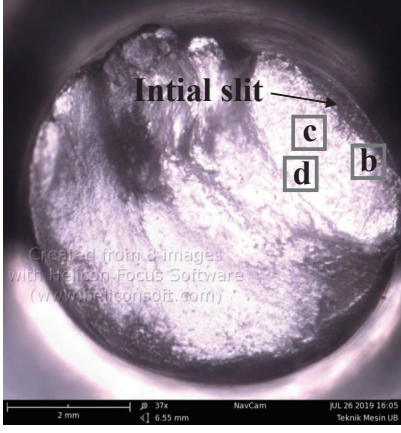

a

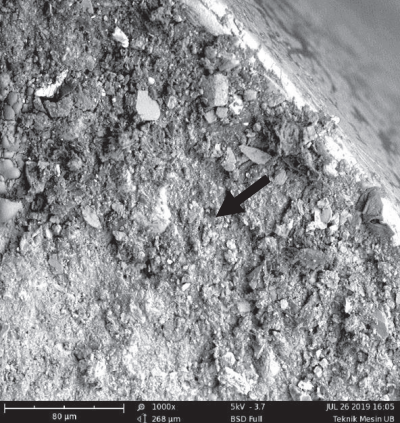

$b$

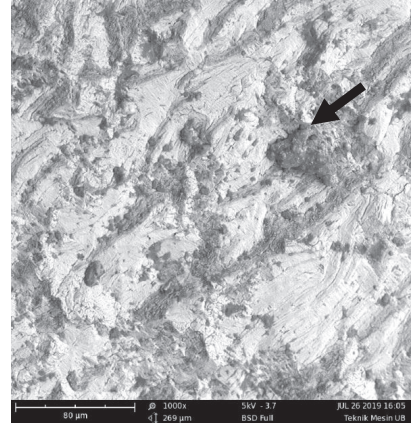

c

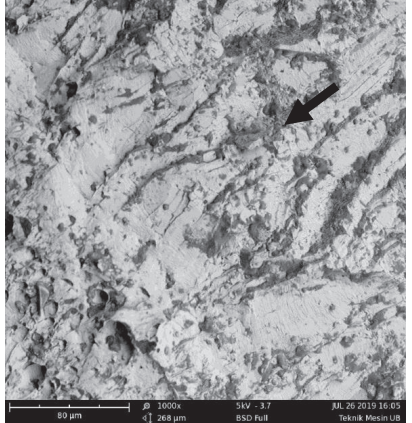

d

Fig. 16. SEM images of the fracture surface of the specimen with chamfer angle of 0 degrees with clamping: $a$ - Overall SEM fracture surface; $b$ - Fatigue fracture surface near slit; $c-$ Fatigue fracture surface in the middle fracture surface; $d-$ Fatigue fracture surface near static/final fracture. (Black arrow is fatigue crack growth direction)

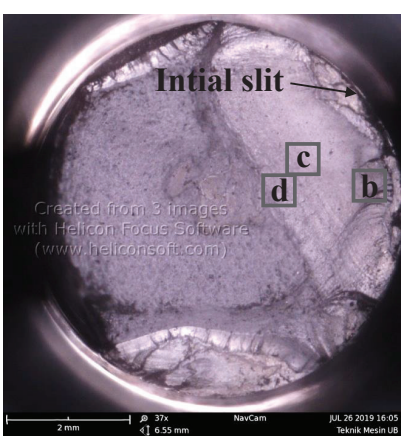

$a$

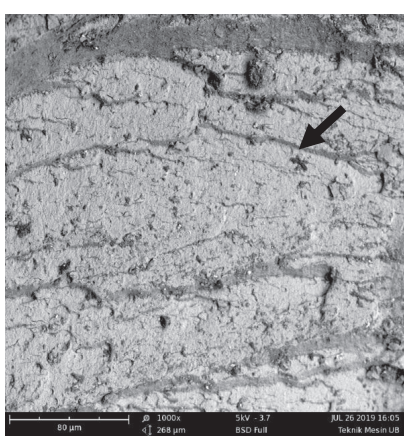

$b$

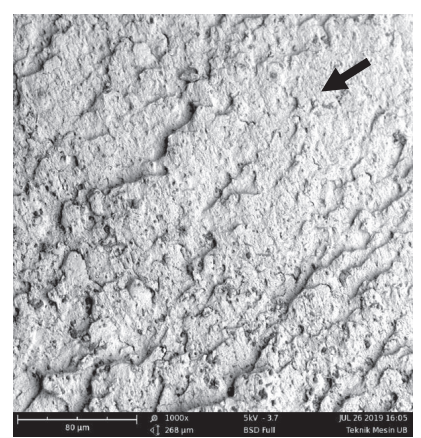

$c$

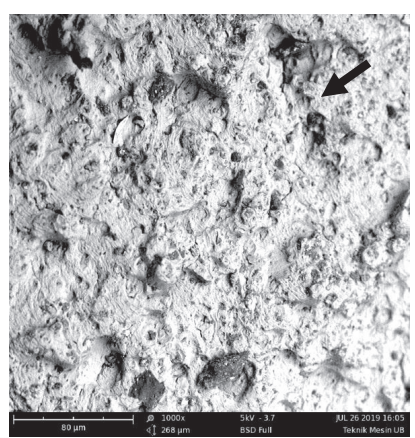

$d$

Fig. 17. SEM images of the fracture surface of the specimen with chamfer angle of 30 degrees with clamping:

$a$ - Overall SEM fracture surface; $b$ - Fatigue fracture surface near slit; $c$ - Fatigue fracture surface in the middle fracture surface; $d-$ Fatigue fracture surface near static/final fracture. (Black arrow is fatigue crack growth direction)

From Fig. 15-17, it can be observed that the specimen with the lowest fatigue crack growth rate has the widest fatigue fracture region. In the low-magnification images, it can be seen more clearly that the fatigue fracture area is flatter than the static fracture region. Under higher magnification, it is evident that the fatigue fracture surface of the specimen with a chamfer angle of 30 degrees has a flat fracture surface with clearer striation (Fig. 17, $c, d$ ). Near the static fracture, the SEM images show dimples in the surface, which indicate that static fracture occurred at the site (Fig. 16, $d$ ). The fatigue fracture has a different appearance in every specimen. It is supposed that the different microstructures in the fractured area appear as a result of the different friction welding conditions, which are affected by the chamfer and the clamping condition.

\section{Discussion of the experimental results}

The results of the experiments show that the use of hydraulic clamping can remove nearly all the flash at the weld joint, particularly for the specimen with a one-sided chamfer angle of 30 degrees. It might occur due to the use of two clamping blocks that formed a half-circle. When the hydraulic piston pushed the two blocks that press the flash of the weld joint, the flash was moved to the two sides of the weld joint, where two blocks of the die clamp meet. In the case of the specimen with a chamfer angle of 30 degrees, the presence of a valley at the interface meant that the flash filled the valley, and only a small volume of flash came out of the interface. When the two blocks of the clamp pressed the flash, only a very small portion of flash remained on the weld joint (Fig. 9, $c$ ). Thus, the chamfer angle contributes to minimizing the flash compared to the specimen without a chamfer angle.

Introducing clamping and a one-sided chamfer angle yielded CDFW joints with higher tensile strength. The clamping process was applied before the upset stage, so the weld joint endures two types of plastic deformation caused by the lateral compression from hydraulic powered clamping and the upset pressure. Two types of plastic deformation could in turn double the effect of strain hardening on the weld joint, increasing the tensile strength of the CDFW joint. Meanwhile, a smaller chamfer angle, e. g., 30 degrees, leads to a smaller initial friction area, so that the temperature of the specimen is lower (Fig. 11). The lower temperature at the weld joint produces less softening of the aluminum, and thus, the tensile strength of the weld joint increases.

Specimens with higher tensile strength also exhibited higher fatigue strength and resistance. Thus, the specimen with maximum tensile strength, with a chamfer angle of 30 degrees, had the lowest fatigue crack growth rate. Macro observation of the fracture surface and SEM images confirmed that the fatigue fracture area of the specimen with higher tensile strength was wider than that of the specimen with lower tensile strength (Fig. 14). It is thought that a higher degree of plastic deformation due to the clamping and upset pressure during the CDFW process produces a higher density of dislocations, which can increase the tensile strength of the weld joint. Different microstructures in the weld joint resulting from the CDFW process affect the appearance of the fatigue fracture of the joint. The CDFW joint specimen with the higher tensile strength had a wider area of fatigue fracture, and a flat fracture surface with clear striation was observed. 
The friction welding using one-side chamfer, the clamping process before the upset pressure stage proposed in this study, was proved to remove almost all the flash of the weld joint and increase the tensile strength of the weld joint. The prospect that will be opened up is the opportunity to apply this method to increase the strength of the weld joint of other metals besides aluminum. This proposed method has advantages over the conventional friction welding on aluminum, such as reported in $[9,10,12,17]$ that produced surrounded flash at the weld joint interface that needs more time to remove the flash by machining. The proposed method can be an alternative solution to remove almost all the flash at the weld joint interface, to increase the tensile strength and to reduce the fatigue crack growth rate of the aluminum weld joint. However, the limitation of the research is the result of the experiments still based on the friction welding process on A6061 aluminum alloy and used one variation of friction time and need a hydraulic clamping tool to remove the flash. Because of the one value of friction time used, the result of experiments such as tensile strength and fatigue crack growth rate can be obtained limited in this condition. Therefore, friction welding using a clamping method with longer friction time will be conducted in the near future to search the higher tensile strength of the friction weld joint. Besides, the proposed method will be developed in order to remove all the flash at the weld joint interface, but it needs to work in designing new dies and clamping tool.

\section{Conclusions}

1. The tensile strength of the CDFW joint specimen using the round bar A6061 with a one-sided chamfer angle and clamping was higher than that of the specimen without a chamfer or clamping. The maximum tensile strength of $220 \mathrm{MPa}$ occurred in the specimen with a one-sided chamfer angle of 30 degrees that underwent clamping. The hydraulic clamping process can increase the tensile strength of the weld joint and remove almost all of the flash for the CDFW specimen with a one-sided chamfer angle of 30 degrees.

2. Weld joint specimens with the highest tensile strength, such as the specimen with a chamfer angle of 30 degrees and clamping, showed the slowest fatigue crack growth rate. The fatigue fracture area of the specimen with higher tensile strength and smaller fatigue crack growth rate is wider than that of the specimen with lower tensile strength and faster fatigue crack growth.

3. Higher tensile strength and lower fatigue crack growth rate in the A6061 CDFW specimen might occur, due to effect of small one-sided chamfer angle, which produces a lower temperature near the weld joint and a double effect of plastic deformation on the weld joint from the hydraulic-powered clamping process and upset pressure during the CDFW process. The appearance of the fatigue fracture surface was affected by the state during the CDFW process. The fatigue surface of the specimen with high tensile strength and lower fatigue crack growth rate was flatter, and the striations are found more evident.

\section{Acknowledgments}

The authors would like to acknowledge research funding from the General Directorate of Research and Development Empowerment, Directorate of Research and Community Service, Ministry of Research, Technology and Higher Education, the Republic of Indonesia Grant. No. 167/SP2H/LT/ DPRM/2019, 11 March 2019.

\section{References}

1. Nicholas, E. D. (2003). Friction Processing Technologies. Welding in the World, 47 (11-12), 2-9. doi: https://doi.org/10.1007/bf03266402

2. Maalekian, M. (2007). Friction welding - critical assessment of literature. Science and Technology of Welding and Joining, 12 (8), 738-759. doi: https://doi.org/10.1179/174329307x249333

3. Yilbas, B. S., Sahin, A. Z. (2014). Friction welding. Thermal and metallurgical characteristics. Springer. doi: https://doi.org/ 10.1007/978-3-642-54607-5

4. Bauccio, M. (Ed.) (1993). ASM Metals Reference Book. ASM International, 614.

5. Barnes, T. A., Pashby, I. R. (2000). Joining techniques for aluminium spaceframes used in automobiles. Journal of Materials Processing Technology, 99 (1-3), 62-71. doi: https://doi.org/10.1016/s0924-0136(99)00367-2

6. Uday, M. B., Ahmad Fauzi, M. N., Zuhailawati, H., Ismail, A. B. (2010). Advances in friction welding process: a review. Science and Technology of Welding and Joining, 15 (7), 534-558. doi: https://doi.org/10.1179/136217110x12785889550064

7. Sahin, M., Akata, H. E., Gulmez, T. (2007). Characterization of mechanical properties in AISI 1040 parts welded by friction welding. Materials Characterization, 58 (10), 1033-1038. doi: https://doi.org/10.1016/j.matchar.2006.09.008

8. Lin, C. B., Mu, C. K., Wu, W. W., Hung, H. C. (1999). The effect of joint design and volume fraction on friction welding properties of A360/SiC (p) composites. Welding Journal, 78 (3), 100-108.

9. Irawan, Y. S., Wirohardjo, M., Ma'arif, M. S. (2012). Tensile Strength of Weld Joint Produced by Spinning Friction Welding of Round Aluminum A6061 with Various Chamfer Angles. Advanced Materials Research, 576, 761-765. doi: https://doi.org/10.4028/ www.scientific.net/amr.576.761

10. Irawan, Y. S., Amirullah, M., Gumilang, G. B. D., Oerbandono, T., Suprapto, W. (2016). Torsion strength of continuous drive friction weld joint of round bar aluminum A6061 affected by single cone geometry of friction area. AIP Conference Proceedings, 1717, 040010. doi: https://doi.org/10.1063/1.4943453

11. Callister, W. D. (2001). Fundamentals of Materials Science and Engineering. John Wiley \& Sons Inc.

12. Yamamoto, Y., Ochi, H., Sawai, T., Yamaguchi, H., Ogawa, K. (2007). Fatigue Strength of Friction-Welded 6061 Aluminum Alloy Joints. MATERIALS TRANSACTIONS, 48 (11), 2909-2913. doi: https://doi.org/10.2320/matertrans.l-mra2007880

13. Mercan, S., Aydin, S., Özdemir, N. (2015). Effect of welding parameters on the fatigue properties of dissimilar AISI 2205-AISI 1020 joined by friction welding. International Journal of Fatigue, 81, 78-90. doi: https://doi.org/10.1016/j.ijfatigue.2015.07.023 
14. Zhang, Y., Sakai, T., Osuki, H., Yamamoto, T., Kokubu, A. (2011). Very High Cycle Fatigue Characteristics of Zr-Base Bulk Amorphous Alloy in Rotating Bending. Journal of Solid Mechanics and Materials Engineering, 5 (10), 519-533. doi: https://doi.org/ 10.1299/jmmp.5.519

15. Standard Methods for Mechanical Testing of Welds (2007). Miami: American Welding Society, 2007.

16. Kuhn, H., Medlin, D. (Eds.) (2000). ASM Handbook Volume 8: Mechanical Testing and Evaluation. Ohio: ASM International, 998.

17. Rafi, H. K., Ram, G. D. J., Phanikumar, G., Rao, K. P. (2010). Microstructure and tensile properties of friction welded aluminum alloy AA7075-T6. Materials \& Design (1980-2015), 31 (5), 2375-2380. doi: https://doi.org/10.1016/j.matdes.2009.11.065

\begin{tabular}{|c|}
\hline 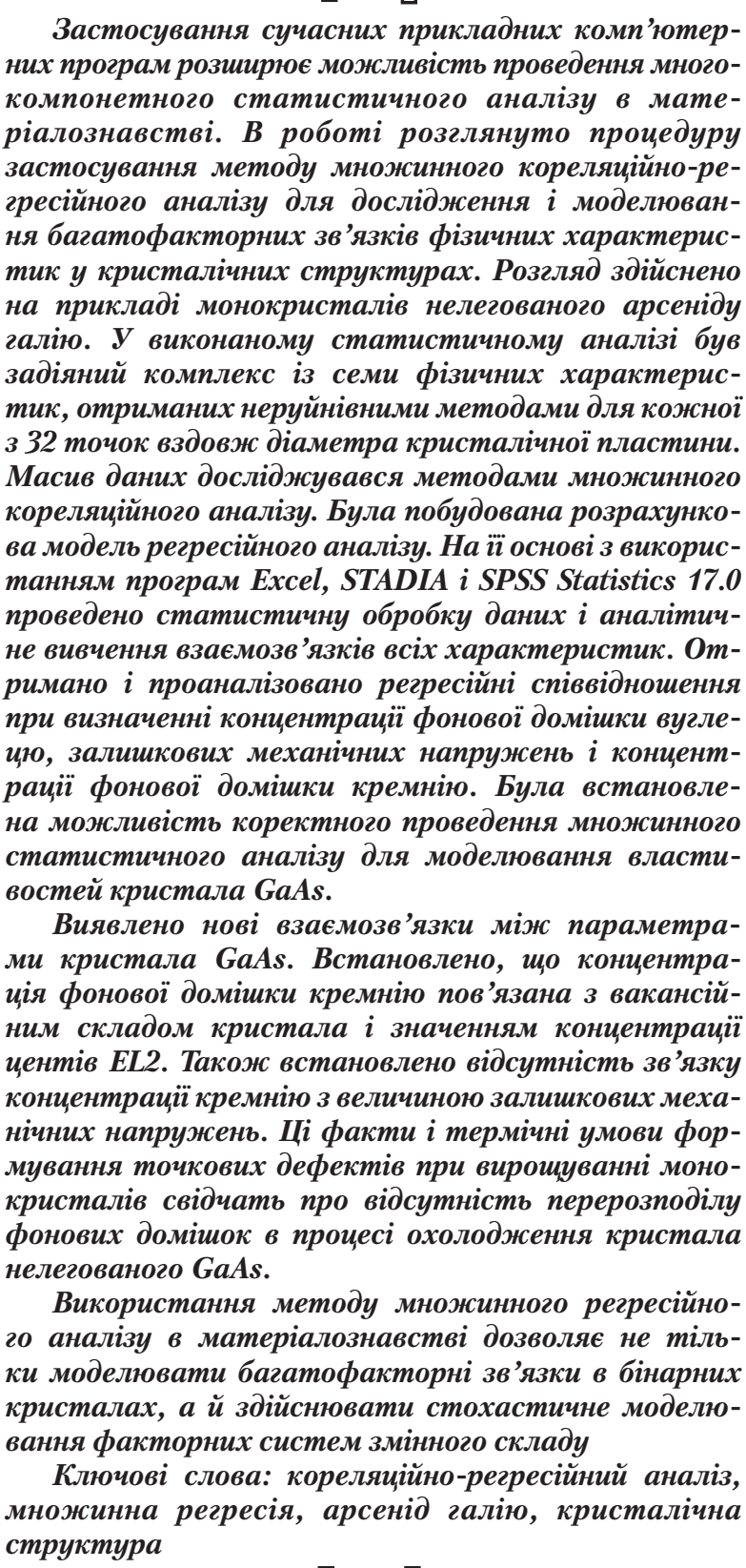 \\
\hline
\end{tabular}

Received date 25.11.2019

Accepted date 19.12.2019

Published date 26.12.2019

1. Introduction

There is no doubt that in modern materials science modeling of the structural properties of crystals occupies
UDC 631:331.4+ 621.315

DOI: $10.15587 / 1729-4061.2019 .188512$

APPLICATION OF MULTIPLE CORRELATION ANALYSIS METHOD TO MODELING THE PHYSICAL PROPERTIES OF CRYSTALS (ON THE EXAMPLE OF GALLIUM ARSENIDE)

M. Litvinova

Doctor of Pedagogical Sciences,

PhD (Physics and Mathematics), Associate Professor*

E-mail: Imb965@gmail.com

N. Andrieieva

$\mathrm{PhD}$, Associate Professor

Department of Heat Engineering**

V. Z a vod y a n n y i

$\mathrm{PhD}$, Associate Professor

Department of Physics and General Engineering Disciplines

Kherson State Agrarian University

Stritenska str., 23, Kherson, Ukraine, 73006

S. Lo i

Associate Professor Department of Welding**

O. S h t a n k o

$\mathrm{PhD}$, Associate Professor*

*Department of Software Engineering,

Physics and Mathematics**

**Kherson Branch of Admiral Makarov National

University of Shipbuilding

Ushakova ave., 44, Kherson, Ukraine, 73022

Copyright (C) 2019, M. Litvinova, N. Andrieieva, V. Zavodyannyi, S. Loi, O. Shtanko

This is an open access article under the CC BY license (http://creativecommons.org/licenses/by/4.0)

a fundamentally important place in the process of improving the technologies for their preparation and application. A significant problem in the correct analysis of the structure and corresponding physical parameters of crystals is the 